\title{
Formic Acid Oxidation of Electrodeposited Platinum Nanostructures on Graphene Oxide Modified Electrode in Acid Medium
}

\author{
Perumal Rameshkumar, Raju Praveen, Ramasamy Ramaraj
}

\begin{abstract}
In this report, we investigated an electrochemical oxidation of formic acid using electrodeposited platinum (Pt) nanostructures on graphene oxide (GO) coated glassy carbon $(G C)$ electrode. The modified electrode is well characterized with the aid of cyclic voltammetry $(\mathrm{CV})$, scanning electron microscopy (SEM), X-ray diffraction (XRD) and Raman analyses. A crystalline flower-like Pt nanostructures were found on $G O$ modified electrode. The GO-Pt modified electrode displayed improved catalytic current signal in formic acid oxidation than the bare GC and Pt nanastrutures modified electrodes. The loading of GO amount dependent catalytic performance was studied to optimize the GO amount for the efficient electrocatalytic activity. The mass activity of the GO-Pt modified electrode is 2.2 times higher than the Pt modified electrode in formic acid electrooxidation. The GO-Pt nanostructures show good stability in amperometric i-t curve and consequently, show the higher turnover number than the only Pt modified electrode.
\end{abstract}

Keywords: Pt nanostructures, graphene oxide, formic acid oxidation, electrodeposition, fuel cells.

\section{INTRODUCTION}

$\mathrm{F}_{\text {uel cells are commonly known to be a key power source }}$ because of their low pollution and efficient energy conversion. A lot of efforts has been made towards the development of efficient fuel cell anodic catalysts for electrooxidation of formic acid [1,2], methanol [3,4] and ethanol $[5,6]$. In recent decades, direct formic acid fuel cells (DFAFCs) have received much concern due to their less sensitive to fuel crossover and have a higher theoretical voltage when compared to direct methanol fuel cells (DMFCs) [7]. Moreover, DFAFCs are the viable energy sources to be applied in stationary and portable electronic devices and they are capable of achieving high power density under ideal conditions [8]. Hence, the study of electrooxidation of formic acid using a highly selective and active electrocatalysts has become an important research because of its potential application in DFAFCs. Noble metal nanocatalysts, mainly Pt and Pd [2, 7, 9-11], have been enormously applied in fuel cells due to their interesting electrocatalytic behavior in formic acid oxidation. $\mathrm{Pt}$ is considered as an active element for the adsorption of formic acid and it is frequently used as an electrocatalyst because of its high acid tolerance.

Carbon materials are frequently preferred as supporting

Revised Manuscript Received on December 05, 2019

* Correspondence Author

Perumal Rameshkumar*, Department of Chemistry, School of Advanced Sciences, Kalasalingam Academy of Research and Education, Krishnankoil - 626 126, India. Email: rameshkumar0212@gmail.com

Raju Praveen, School of Chemistry, Madurai Kamaraj University Madurai-625 021, India. Email:rajupraveen89@gmail.com

Ramasamy Ramaraj**, School of Chemistry, Madurai Kamaraj University, Madurai - 625 021, India. Email: ramarajr@yahoo.com material for noble metal nanostructures to minimize the cost and to develop efficient fuel cells. Even though the introduction of carbon materials could increase the diffusion layer thickness, and consequently, could enhance the resistivity in mass transfer of analytes and products the optimization of carbon materials concentration on the electrode surface yields high efficiency in the fuel cell reactions [12]. Nowadays, the usage of graphene as support material for metals is highly encouraged in the field of nanoresearch because of its amazing electrical and mechanical properties, and large surface area [13,14]. Graphene oxide, derivative of graphene, has also received large consideration because of its distinctive properties and large surface area and moreover, it is cheap to prepare on a large-scale $[15,16]$. GO is a promising material for environmental applications $[17,18]$ and for catalytic carriers in chemical reactions $[19,20]$. GO-metal nanocomposites are widely used in electrocatalysis because of their unique features including chemical stability, high electrical conductivity and low cost [21-23]. Many successful attempts have been completed to prepare metal nanoparticles such as $\mathrm{Ag}$ [24], Au [25], Pt [26] and Pd [11] incorporated GO matrix and used for electro-catalytic applications. Moreover, GO-metal nanocomposites, in particular, GO-Pt nanocomposite materials have extensively been utilized for fuel cell applications [3,4,27,28]. For the synthesis of nanocomposite, electrodeposition of metal is highly preferred due to its low cost and easier control than chemical reduction method. Different shaped micro/nanostructures can easily be prepared by the electrodeposition method [29].

In the present work, an electrocatalyst consisting of GO and $\mathrm{Pt}$ nanostructures were formed through a simple electrochemical method on GC electrode surface. The Pt nanostructures showed electrochemical response in formic acid oxidation and the response was improved due to the presence of GO matrix. The film thickness of GO was optimized for the minimization of mass transfer resistance. The higher mass activity, stability and higher turnover number indicated that the electrochemically prepared GO-Pt nanocatalyst has the potential to be used in DFAFCs.

\section{A. Chemicals}

\section{MATERIALS AND METHODS}

Chloroplatinic acid hexahydrate $\left(\mathrm{H}_{2} \mathrm{PtCl}_{6} \cdot 6 \mathrm{H}_{2} \mathrm{O}\right)$ was procured from Sigma-Aldrich. Graphite powder was urchased from Alfa Aesar. Formic acid, sulfuric acid $\left(\mathrm{H}_{2} \mathrm{SO}_{4}\right.$, $98 \%)$, sodium nitrate $\left(\mathrm{NaNO}_{3}\right)$, potassium permanganate $\left(\mathrm{KMnO}_{4}\right)$ and hydrogen peroxide $\left(\mathrm{H}_{2} \mathrm{O}_{2}\right)$ were procured from Merck. Glassware was carefully cleaned by aqua regia and rinsed using doubly distilled water before use.

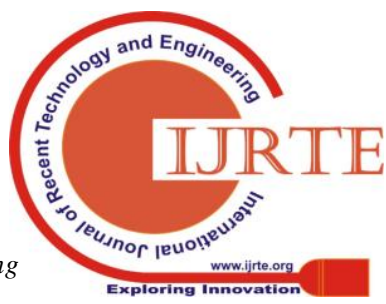




\section{Formic Acid Oxidation of Electrodeposited Platinum Nanostructures on Graphene Oxide Modified Electrode in Acid Medium}

\section{B. Synthesis of GO solution}

GO was synthesized using graphite powder by following modified Hummers method [24]. Briefly, $1 \mathrm{~g}$ of graphite was stirred in $23 \mathrm{~mL}$ of $\mathrm{H}_{2} \mathrm{SO}_{4}$ for $24 \mathrm{~h}$ at room temperature. 100 mg of $\mathrm{NaNO}_{3}$ was introduced to the mixture while stirring. After $30 \mathrm{~min}$, the mixture was preserved below $5{ }^{\circ} \mathrm{C}$ and $3 \mathrm{~g}$ of $\mathrm{KMnO}_{4}$ was added to it. The mixture was further stirred for $30 \mathrm{~min}$ after heating at $35-40{ }^{\circ} \mathrm{C}$. Further, a $46 \mathrm{~mL}$ of water was slowly added during stirring and finally, $140 \mathrm{~mL}$ of water and $10 \mathrm{~mL}$ of $\mathrm{H}_{2} \mathrm{O}_{2}$ were added into the mixture to arrest the reaction. After removing the excess graphite by centrifugation, GO was dispersed in distilled water with a concentration of $0.3 \mathrm{mg} \mathrm{mL}^{-1}$ and the dispersion was sonicated for further use (Note: An optimized amount of 2.5 $\mu \mathrm{g} \mathrm{mL}^{-1} \mathrm{GO}$ solution was used throughout the study).

\section{Fabrication of ITO or GC/GO-Pt modified electrode}

Exactly $5 \mu \mathrm{L}$ of GO solution was dropped on GC electrode surface $\left(0.07 \mathrm{~cm}^{2}\right)$ and dried at room temperature for an hour. For ITO/GO-Pt modified electrode, $57 \mu \mathrm{L}$ of GO solution was coated on $0.8 \mathrm{~cm}^{2}$ ITO surface in order to maintain the same film thickness both on GC and ITO surfaces. Pt nanostructures were electrodeposited on $\mathrm{GO}$ coated electrode using the applied potential of $-0.2 \mathrm{~V}\left(\mathrm{Hg} / \mathrm{Hg}_{2} \mathrm{Cl}_{2}\right)$ for $300 \mathrm{~s}$ in $0.5 \mathrm{M} \mathrm{H}_{2} \mathrm{SO}_{4}$ containing $3 \mathrm{mM} \mathrm{H}_{2} \mathrm{PtCl}_{6}$ as an electrolyte solution. The modified electrode is represented as ITO or GC/GO-Pt.

\section{Electrochemical measurements}

The electrochemical experiments were carried out using $\mathrm{CH}$ Instruments electrochemical workstation attached with a three-electrode cell compartment. The GC or ITO electrode was used as working electrode. A platinum wire and saturated calomel electrode were counter and reference electrodes, respectively. The electrochemical studies for formic acid oxidation are conducted in $0.5 \mathrm{M} \mathrm{H}_{2} \mathrm{SO}_{4}$ solution with $0.5 \mathrm{M}$ formic acid. Current-time curves of GO-Pt for formic acid oxidation were obtained at respective peak potentials immediately after the collection of cyclic voltammograms.

\section{E. Characterization}

TEM image of GO was obtained through JEOL JEM 2100 instrument $(200 \mathrm{kV})$. ITO electrode was used for the SEM and XRD characterizations of modified electrodes. SEM micrographs of Pt nanostructures modified electrodes were obtained with a JEOL Model JSM-6390LV instrument. The samples were undergone gold sputtering prior to the SEM analysis. XRD analysis was made using a Bruker AXS D8 Advance instrument. Raman spectrum was collected using laser Raman AMAN microscope Labram HR Evolution, Horiba instrument. Electrochemical characterization was performed with a $\mathrm{CH}$ Instruments electrochemical workstation (model-760D).

\section{RESULTS AND DISCUSSION}

\section{A. Formation mechanism of $\mathrm{Pt}$ nanostructures and characterization of GO-Pt}

To characterize presence of $\mathrm{GO}$ in the modified electrode, $\mathrm{CVs}$ of the modified electrode was recorded in $0.5 \mathrm{M} \mathrm{H}_{2} \mathrm{SO}_{4}$ from $-0.6 \mathrm{~V}$ to $-1.2 \mathrm{~V}$ (Fig. 1). A reduction peak appeared at $-0.96 \mathrm{~V}$ during the cathodic scan in the first $\mathrm{CV}$ indicates the reduction of functional groups present in $\mathrm{GO}$ and no redox peaks formed in the second voltammogram. This confirms the presence of $\mathrm{GO}$ at the electrode surface. The electrodeposition of $\mathrm{Pt}$ nanostructures was performed by applying the potential of $-0.2 \mathrm{~V}$ on ITO or GC and ITO/GO or GC/GO electrodes. As the standard redox potential for the $\mathrm{Pt}^{4+} / \mathrm{Pt}$ couple is $+0.74 \mathrm{~V}$ (vs. NHE) the applied potential used in this work can facilely drive the electrodeposition process leading to the formation Pt nanostructures on the electrodes. The nucleation and growth of Pt nanostructures on GC/GO is much controlled because of the presence of functional groups.

The Pt nanostructures show distinctive oxidation peak for platinum oxide at around $+0.93 \mathrm{~V}$ in the positive sweep and the reduction peak at around $+0.45 \mathrm{~V}$ in the negative sweep (Fig. 2). In addition to the redox characteristics of $\mathrm{Pt}$ nanostructures, the peaks for hydrogen adsorption/desorption are appeared between $-0.2 \mathrm{~V}$ and $+0.1 \mathrm{~V}$. The Pt redox peaks associated with hydrogen adsorption/desorption peaks in the given potential region confirm the presence of $\mathrm{Pt}$ at the modified electrodes. The GC/GO-Pt electrode shows higher $\mathrm{Pt}$ redox peak current and this explains that the amount of $\mathrm{Pt}$ nanoparticles is more in GC/GO-Pt modified electrode because of the presence of GO compared to the GC/Pt. The presence of various functional groups present in $\mathrm{GO}$ is responsible for carrying more amount of $\mathrm{Pt}$ during electrodeposition. From these CVs, the electrochemically active surface area (EASA) was calculated from the charges associated with the reduction peaks of Pt oxide. The EASAs for $\mathrm{GC} / \mathrm{Pt}$ and GC/GO-Pt were calculated to be 2.471 and $1.566 \mathrm{~cm}^{2}$, respectively using the following equation.

$\mathrm{EASA}=\mathrm{Q}^{\mathrm{Q}} \mathrm{Q}^{*}$

where, $\mathrm{Q}$ is the charge consumed for the reduction of $\mathrm{Pt}$ oxide monolayer and $\mathrm{Q}^{*}$ is the calibration factor having a value of $420 \mu \mathrm{C} / \mathrm{cm}^{2}$ for $\mathrm{Pt}$.

Further, TEM micrograph of the GO shows the sheet-like structure which indicates the successful exfoliation of GO (Fig. 3A). The morphology of the $\mathrm{Pt}$ nanostructures was identified through SEM analysis (Fig. 3(B\&C)). A stone-like nanostructures with a wide-size distribution were found when Pt electrodeposited on bare ITO and however, a flower-like morphology was seen on GO coated ITO. This confirms the controlled growth of $\mathrm{Pt}$ nanostructures directed by the presence of functional groups of GO. The Pt nanostructures formed on both bare ITO and GO modified ITO showed the high intense diffraction peaks at the $2 \theta$ values of $40.2,46.6$

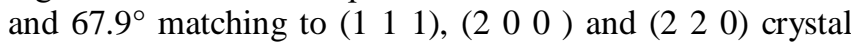
planes of Pt (JCPDS card no. 88-2343) (Fig. 3D). The exposed active crystal facets are highly beneficial for the $\mathrm{Pt}$ nanostructures to be active in a particular catalysis. In addition to the electrochemical characterization, GO was further characterized through Raman spectrum of GO-Pt nanostructures. It showed the typical D and $\mathrm{G}$ bands at 1341 and $1601 \mathrm{~cm}^{-1}$, which are appeared due to lattice defects and $\mathrm{C}-\mathrm{C}$ bond alteration, respectively [30]. The appearance of 2D band indicates the formation of exfoliated GO sheets. Further, higher intensity of D band then $G$ band shows a partial reduction of GO. 


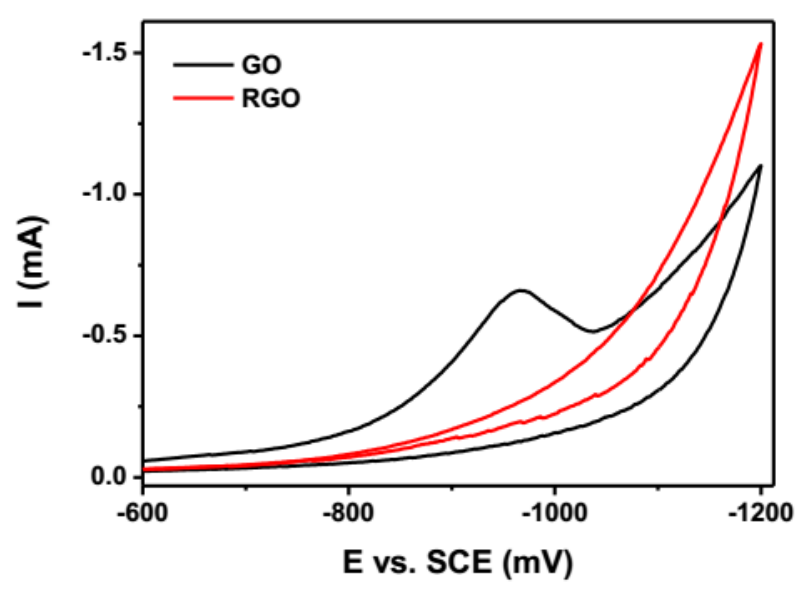

Figure 1. CVs obtained at GC/GO and GC/RGO in $0.5 \mathrm{M}$ $\mathrm{H}_{2} \mathrm{SO}_{4}$ using $50 \mathrm{mV} \mathrm{s}^{-1}$ scan rate.

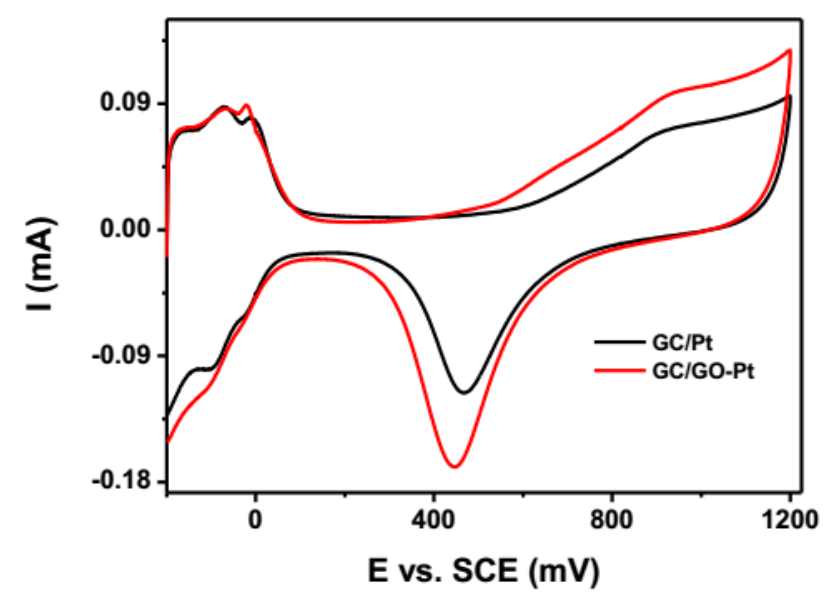

Figure 2. CVs obtained at GC/Pt and GC/GO-Pt in $0.5 \mathrm{M}$ $\mathrm{H}_{2} \mathrm{SO}_{4}$ using $50 \mathrm{mV} \mathrm{s}^{-1}$ scan rate.
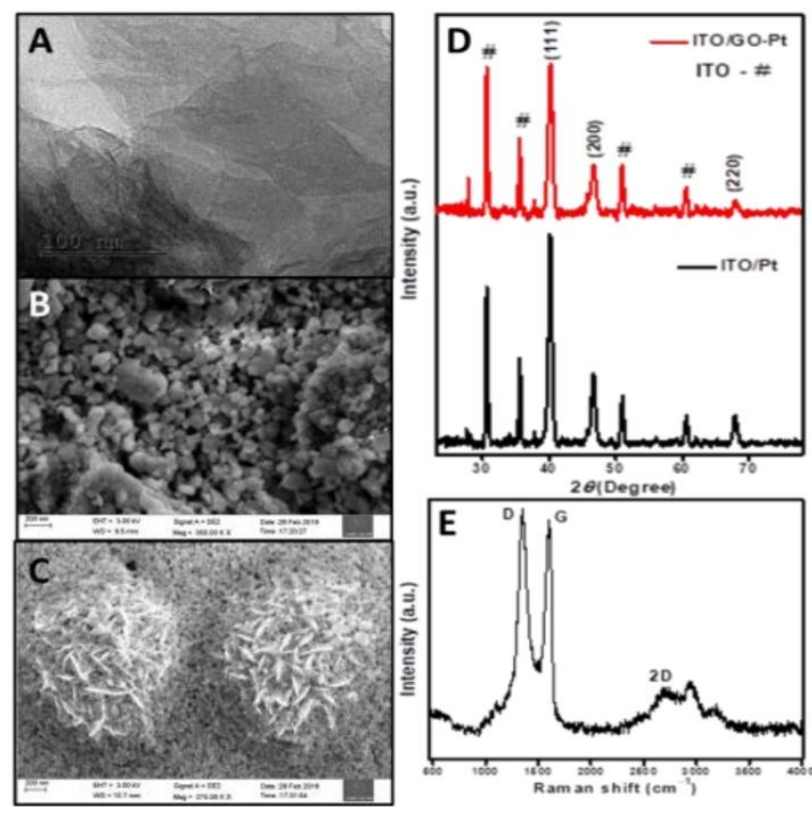

Figure 3. TEM image of GO sheet (A). SEM images of Pt nanostructures formed on bare ITO (B) and ITO/GO modified electrode (C). XRD patterns of ITO/Pt and ITO/GO-Pt modified electrodes (D) and Raman spectrum of GC/GO-Pt modified electrode (E).

\section{B. Electrocatalytic oxidation of formic acid}

In this work, the electrocatalytic oxidation of formic acid is investigated in acid medium using GC/GO-Pt modified electrode. Fig. 4A shows the CVs obtained for $0.5 \mathrm{M}$ formic acid in $0.5 \mathrm{M} \mathrm{H}_{2} \mathrm{SO}_{4}$ with a scan rate of $50 \mathrm{mV} \mathrm{s}^{-1}$. The GC/GO-Pt modified electrode produces better catalytic effect than GC/Pt modified electrode. The identified significant differences in the catalytic peak currents of formic acid oxidation at GC/GO-Pt and GC/Pt modified electrodes were due to the different $\mathrm{Pt}$ surface electronic structure. The surface active sites originated from the flower-like morphology in the presence of GO might also have contributed towards the improved performance of GO-Pt nanostructures in the catalysis. However, bare GC electrode showed no catalytic effect on formic acid. Notably, the GC/GO-Pt modified electrode has not shown any redox behavior in the absence of formic acid (Fig. 4B). It is well known from the literature reports that there are three different path ways for the electrochemical oxidation of formic acid on Pt surface: (i) formation of $\mathrm{CO}_{2}$ with the elimination of two hydrogen atoms, (ii) formation of $\mathrm{CO}$ intermediate and subsequent $\mathrm{CO}$ oxidation, and (iii) formation of formate ion with the removal of hydrogen atom and its oxidation to $\mathrm{CO}_{2}$. Although the mechanism of formic acid oxidation is speculative we can explain the mechanism on the present modified electrodes using the peak currents of cyclic voltammograms. In this work, the electrooxidation of formic acid at both GC/Pt and GC/GO-Pt surfaces follows the same mechanism. The less intense oxidation peak at around +300 $\mathrm{mV}$ is due to the direct oxidation of formic acid to $\mathrm{CO}_{2}$ and the high intense peak at around $+650 \mathrm{mV}$ corresponds to the formation of $\mathrm{CO}_{2}$ through $\mathrm{CO}$ intermediate. The GC/GO-Pt produces higher $\mathrm{CO}$ oxidation current than $\mathrm{GC} / \mathrm{Pt}$. In the reverse sweep, the oxidation of adsorbed intermediates formed during the electrooxidation of formic acid occurs at around $+415 \mathrm{mV}$. In both forward and reverse sweeps, the catalytic activity of the GC/GO-Pt is much better than the $\mathrm{GC} / \mathrm{Pt}$. CVs obtained for $0.5 \mathrm{M}$ formic acid using modified ITO electrodes are shown in Fig. 5. In these electrodes also, the GO/Pt modified ITO displayed a better performance than only Pt modified electrode. The reaction mechanism follows the similar trend in both modified GC and ITO electrodes.

The loading of GO amount on GC was varied to study the effect of GO layer thickness on formic acid oxidation (Fig. $6(\mathrm{~A} \& \mathrm{~B}))$. Although the bulk $0.3 \mathrm{mg} / \mathrm{mL}$ GO coated GC/GO-Pt modified electrode failed to show a better catalytic activity the dilution of GO made a significant improvement in the catalysis than the GC/Pt modified electrode. With an optimum amount of GO $\left(2.5 \mu \mathrm{g} \mathrm{mL}^{-1}\right)$, the catalytic current density is higher and when the dilution goes beyond the optimum level the catalytic activity declines. As the film thickness of diffusion layer is higher in the bulk GO coated modified electrode the electron transfer is poor and with an optimized concentration of GO, the electron transfer is facile which consequently leads to better catalytic response in formic acid oxidation. To study the effect of reduced graphene oxide (RGO), the oxidation of formic acid was performed using GC/RGO-Pt modified electrode. Here, GO is reduced electrochemically by applying 10 continuous potential cycles between -0.5 and $-1.1 \mathrm{~V}$.

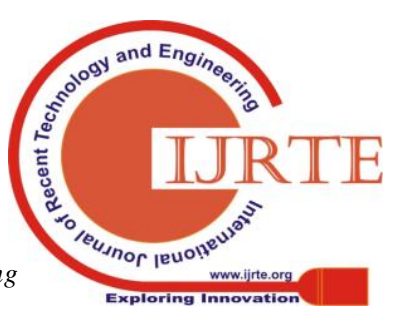


Formic Acid Oxidation of Electrodeposited Platinum Nanostructures on Graphene Oxide Modified Electrode in Acid Medium

Both GC/GO-Pt and GC/RGO-Pt produce the same catalytic effect for formic acid oxidation (Fig. 7). So the electrodeposited Pt nanostructures behave unvaryingly in the formic acid oxidation whether the modified electrode contains GO or RGO in the present investigation. The important electrochemical parameters for the formic acid oxidation are provided in Table 1. It is observed that the mass activity of GC/GO-Pt (53.617 $\left.\mathrm{mA} \mathrm{mg}^{-1}\right)$ is 2.2 times higher than that of GC/GO-Pt $\left(24.156 \mathrm{~mA} \mathrm{mg}^{-1}\right)$.
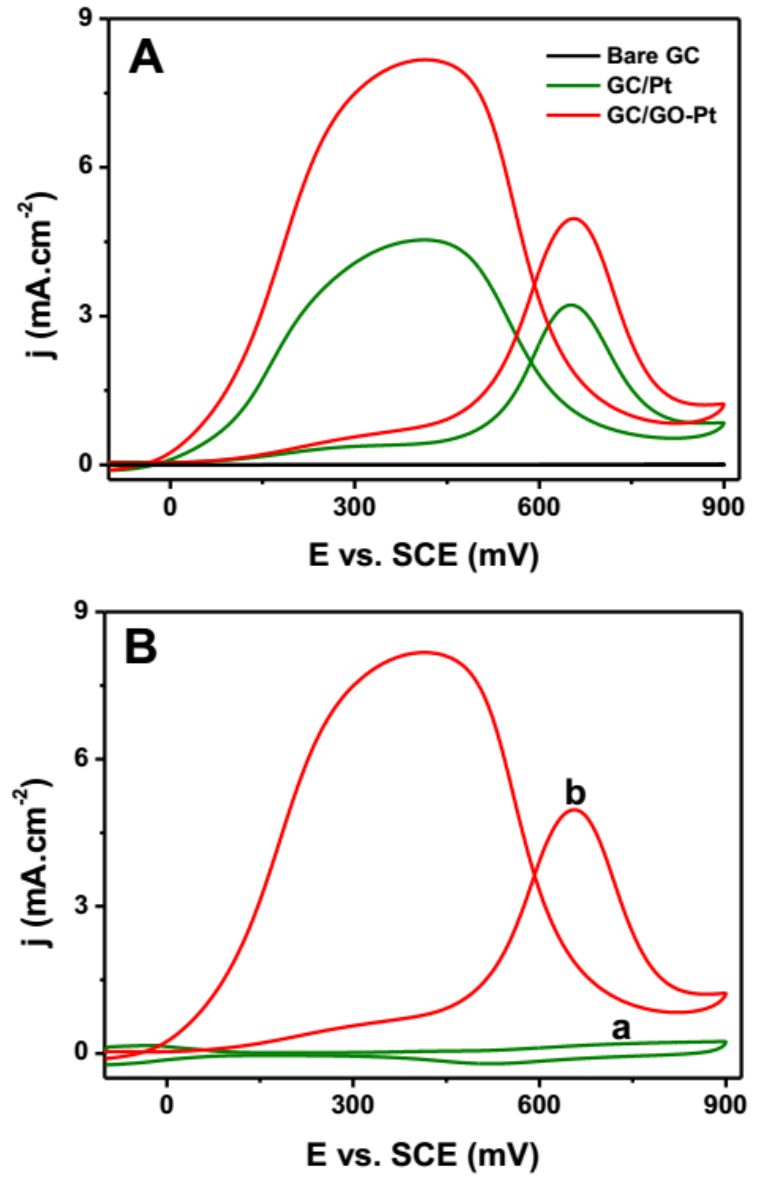

Figure 4. CVs obtained at various modified electrodes for $0.5 \mathrm{M}$ formic acid in $0.5 \mathrm{M} \mathrm{H}_{2} \mathrm{SO}_{4}$ using $50 \mathrm{mV} \mathrm{s}^{-1}$ scan rate (A). CVs obtained at GC/GO-Pt modified electrode in the absence (a) and presence (b) of $0.5 \mathrm{M}$ formic acid in $0.5 \mathrm{M} \mathrm{H}_{2} \mathrm{SO}_{4}$ using $50 \mathrm{mV} \mathrm{s}^{-1}$ scan rate $(\mathrm{B})$.

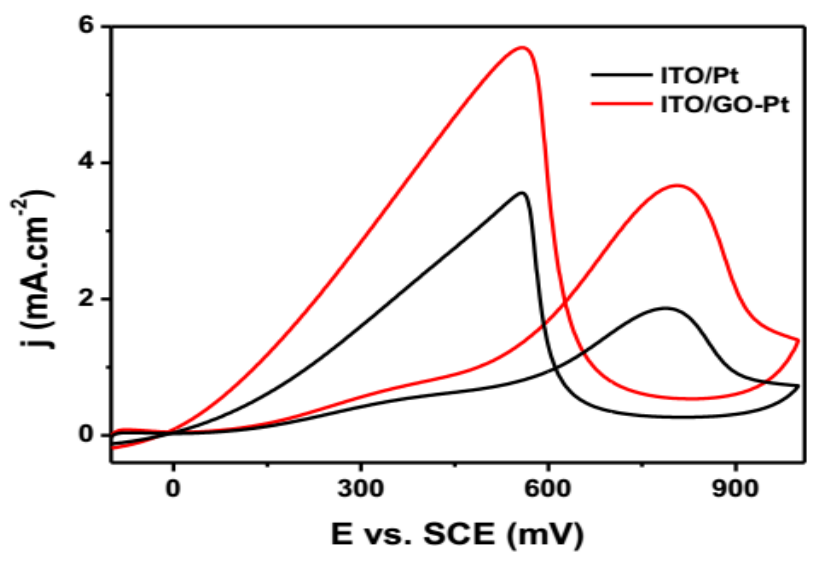

Figure 5. CVs obtained at ITO/Pt and ITO/GO-Pt for 0.5 $M$ formic acid in $0.5 \mathrm{M} \mathrm{H}_{2} \mathrm{SO}_{4}$ using $50 \mathrm{mV} \mathrm{s}^{-1}$ scan rate.
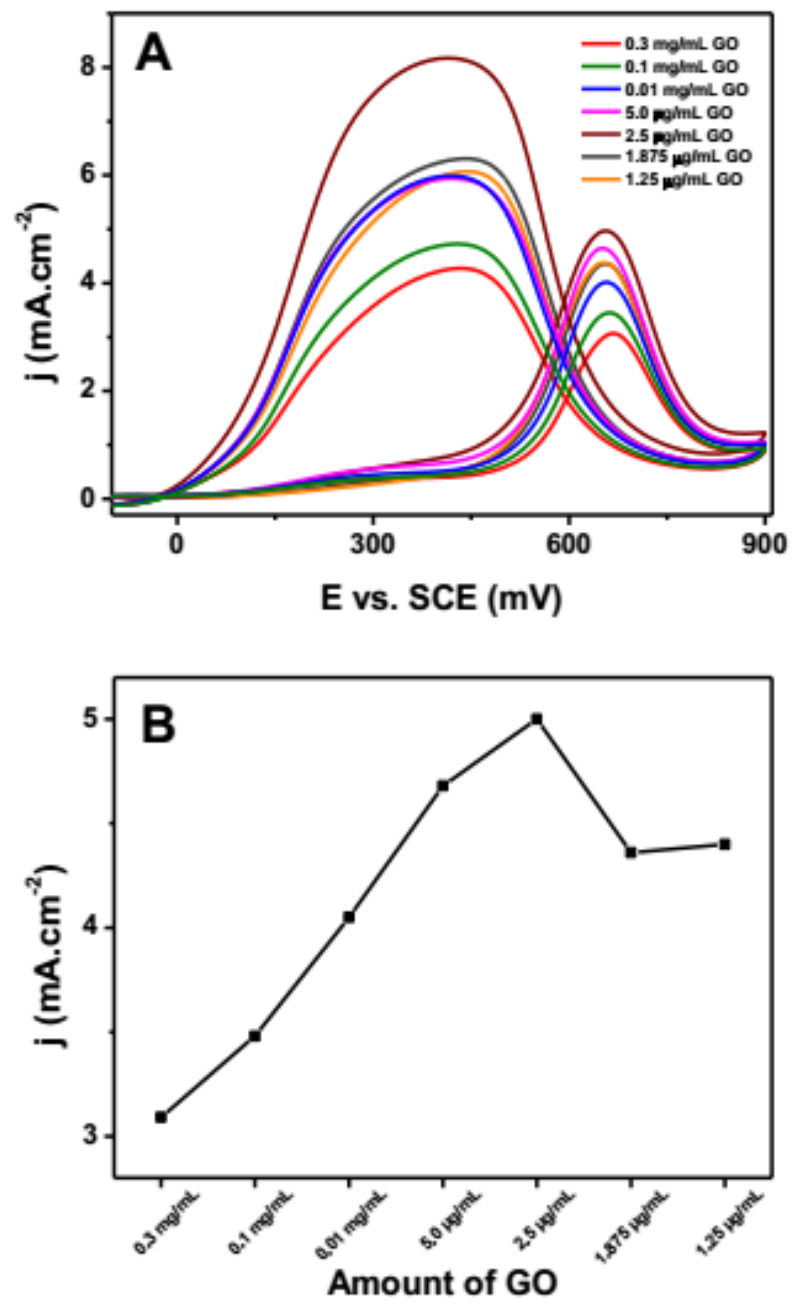

Figure 6. CVs obtained for $0.5 \mathrm{M}$ formic acid at GC/GO/Pt modified electrode in $0.5 \mathrm{M} \mathrm{H}_{2} \mathrm{SO}_{4}$ using 50 $\mathrm{mV} \mathrm{s}^{-1}$ scan rate (A). Calibration plot of current density versus GO content $(B)$.

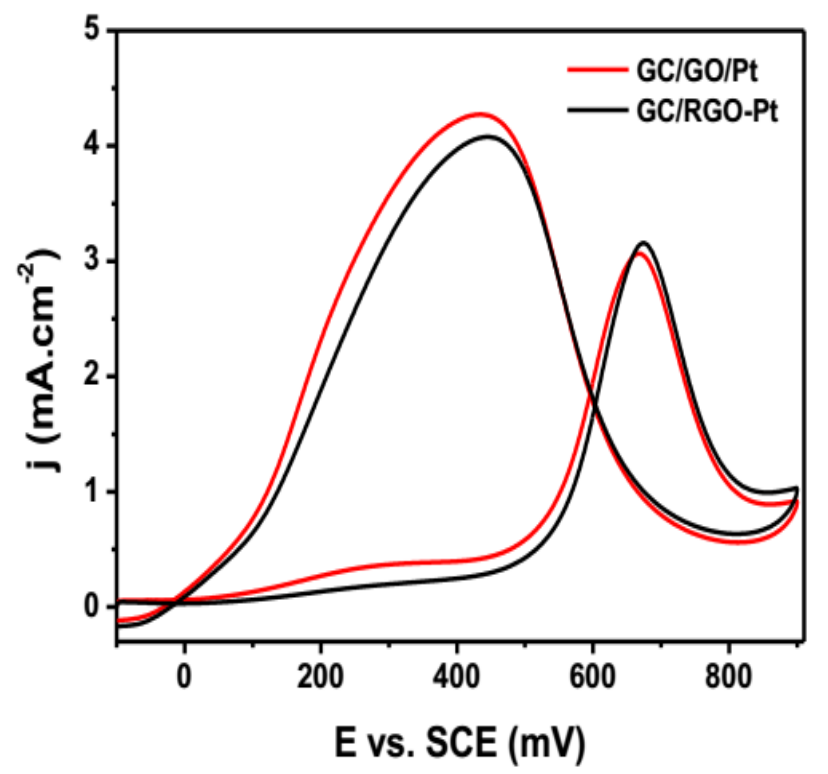

Figure 7. CVs obtained for $0.5 \mathrm{M}$ formic acid at GC/GO-Pt and GC/RGO-Pt in $0.5 \mathrm{M} \mathrm{H}_{2} \mathrm{SO}_{4}$ using $50 \mathrm{mV}$ $\mathrm{s}^{-1}$ scan rate.

Published By:

Blue Eyes Intelligence Engineering \& Sciences Publication

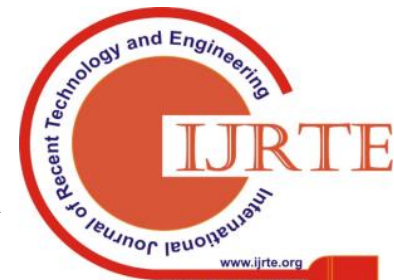


The CVs were recorded in $0.5 \mathrm{M}$ formic acid and $0.5 \mathrm{M}$ $\mathrm{H}_{2} \mathrm{SO}_{4}$ at GC/GO-Pt electrode with different scan Rates (20, 50,100, 150 and $200 \mathrm{mV} \mathrm{s}^{-1}$ ) (Fig. 8A). The peak current density is increased with increasing the scan rate and the values of square root of scan rates show a linear relationship with the current densities (Fig. 8B). It is suggested that the oxidation of formic acid at the present modified electrode may be a diffusion controlled process. A significant potential shift along with increasing in the peak current density is observed while increasing the scan rate. The relationship between peak potential and $\log (v)$ corresponding to the modified electrode is correlated in Fig. 8C. It is observed that the potential values increase linearly with $\log (v)$ and this suggests that the oxidation is irreversible.

Table 1. Electrochemical parameters of formic acid oxidation at the modified electrodes.

\begin{tabular}{|l|l|l|l|l|}
\hline $\begin{array}{c}\text { Modified } \\
\text { electrode }\end{array}$ & $\begin{array}{c}\text { Active } \\
\text { mass } \\
\left(\mathrm{mg} \mathrm{cm}^{-2}\right)\end{array}$ & $\begin{array}{c}\text { Peak current } \\
\text { density } \\
\left(\mathrm{mA} \mathrm{cm}^{-2}\right)\end{array}$ & $\begin{array}{c}\text { Mass } \\
\text { activity } \\
\left(\mathrm{mA} \mathrm{mg}^{-1}\right)\end{array}$ & $\begin{array}{c}\text { TO } \\
\left(\begin{array}{c}\mathrm{N} \\
\left(\mathrm{s}^{-1}\right)\end{array}\right.\end{array}$ \\
\hline GC/Pt & 0.128 & 3.092 & 24.156 & 0.50 \\
\hline GC/GO-Pt & 0.089 & 4.772 & 53.617 & 1.58 \\
\hline
\end{tabular}

The electrochemical stability of the modified electrode was studied by recording the current-time curves at the peak potential (Fig. 9). The current density decay is lower for GC/GO-Pt compared to the GC/Pt. The stable current densities are observed as 0.66 and $0.21 \mathrm{~mA} \mathrm{~cm}^{-2}$ for GC/GO-Pt and GC/Pt modified electrodes, respectively at 3600 s. The turnover number (TON) was calculated to evaluate the catalytic activity and stability of the $\mathrm{Pt}$ nanostructures modified electrodes towards formic acid oxidation. The TON, the number of formic acid molecules that react per catalyst surface site, is calculated from the following equation [29].

$$
\operatorname{TON}\left(\frac{\text { molecules }}{\text { site }}\right)=\frac{\mathrm{i} \times 6.023 \times 10^{23}}{\mathrm{nF} \times 1.3 \times 10^{15}}
$$

where $\mathrm{i}$ is the steady-state current density of the modified electrode at $3600 \mathrm{~s}$ in Fig. 9, $\mathrm{n}$ is the number electrons evolved from the oxidation of $1 \mathrm{M}$ formic acid, $\mathrm{F}$ is Faraday constant and the number $1.3 \times 1015 \mathrm{~cm}^{-2}$ is the density of topmost atoms of an ideal Pt $\left(\begin{array}{lll}1 & 0 & 0\end{array}\right)$ surface. The TONs of GC/GO-Pt and GC/Pt are calculated as 1.58 and $0.50 \mathrm{~s}^{-1}$, respectively (Table1). The higher TON observed for GC/GO-Pt than GC/Pt which explains that GC/GO-Pt oxidizes more number of formic acid molecules than GC/Pt for the same period with the same number of active $\mathrm{Pt}$ sites.
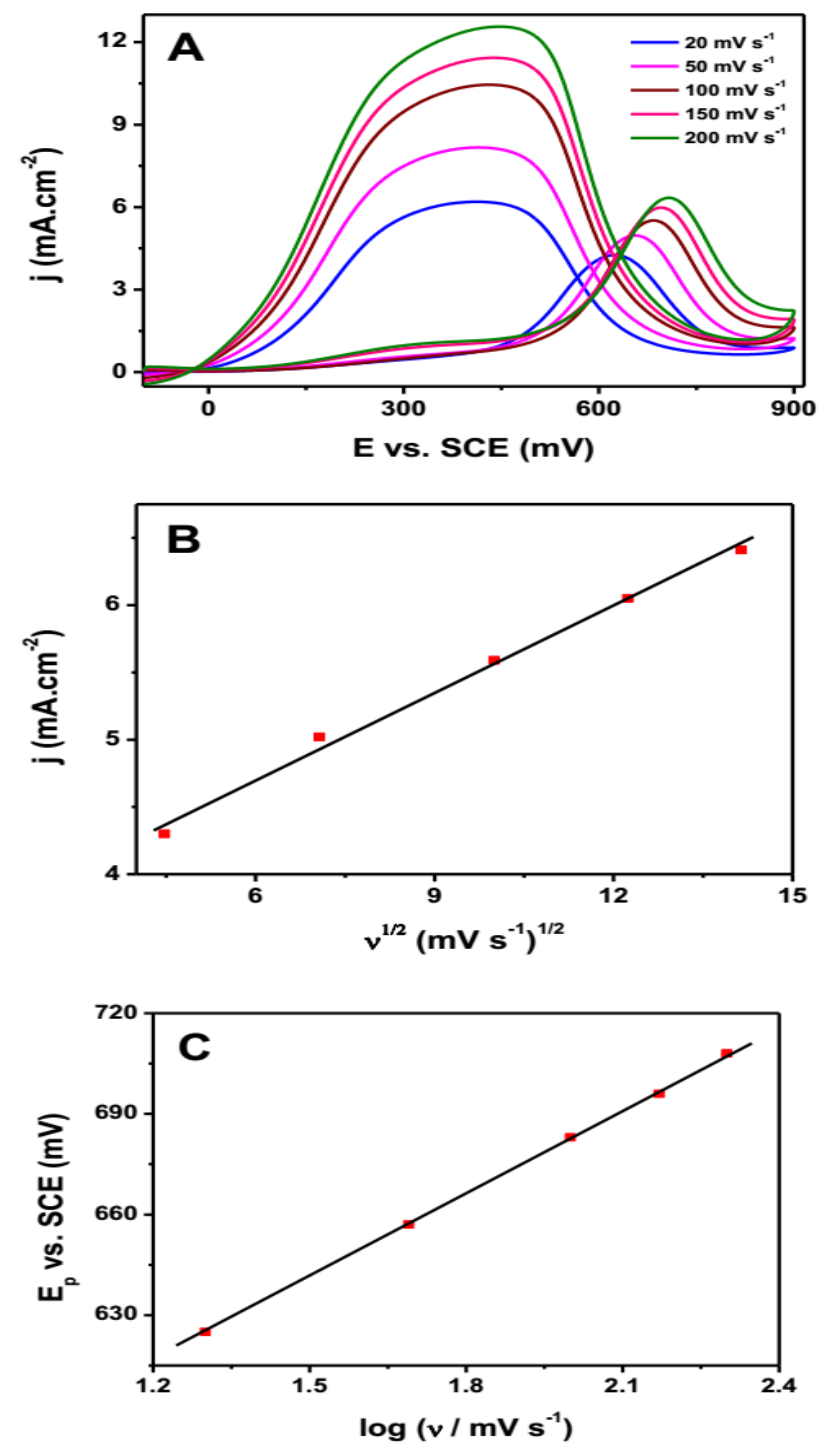

Figure 8. CVs obtained for $0.5 \mathrm{M}$ formic acid at GC/GO-Pt in $0.5 \mathrm{M} \mathrm{H}_{2} \mathrm{SO}_{4}$ with various scan rates (20, $50,100,150$ and $\left.200 \mathrm{mV} \mathrm{s}^{-1}\right)(\mathrm{A})$. Corresponding calibration plots ( $\mathrm{B}$ and $\mathrm{C})$.

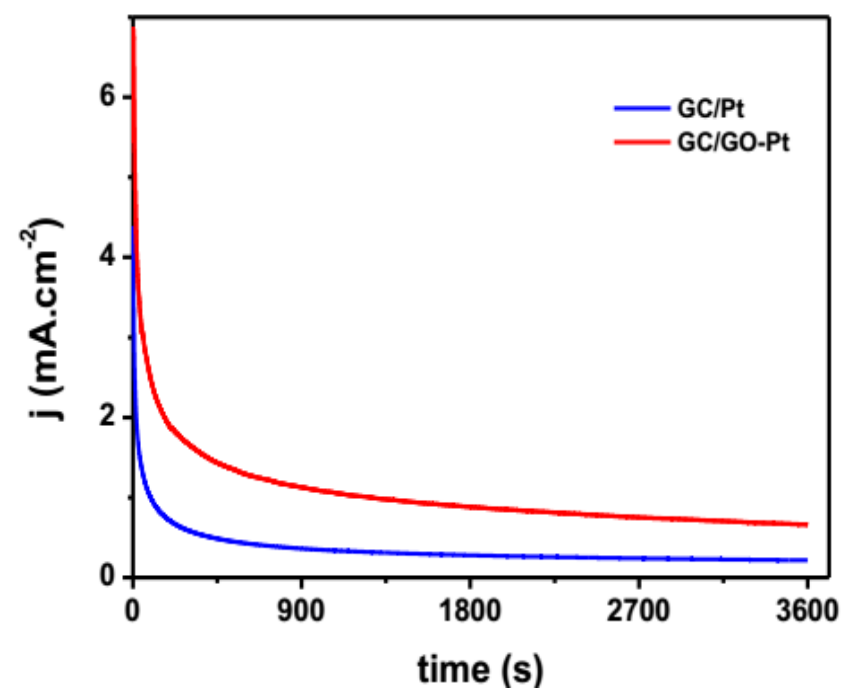

Figure 9. Current-time curves recorded for $0.5 \mathrm{M}$ formic acid at the corresponding peak potentials. 


\section{Formic Acid Oxidation of Electrodeposited Platinum Nanostructures on Graphene Oxide Modified Electrode in Acid Medium}

\section{CONCLUSION}

In conclusion, an electrooxidation of formic acid using electrodeposited Pt nanostructures on GO coated GC or ITO electrode was reported. The nanostructured $\mathrm{Pt}$ was identified through SEM image and the nucleation of Pt nanostructures was influenced by GO layer. Irrespective of the nature of carbon support (GO or RGO), the modified electrode produced same response in the electrocatalytic oxidation of formic acid. This indicated that $\mathrm{GO}$ or RGO did not involve in the electron transfer process and however, it helped in controlling the morphology and crystal growth of $\mathrm{Pt}$ nanostructures. Under optimized conditions, the GO-Pt modified electrode showed the mass activity of $53.617 \mathrm{~mA}$ $\mathrm{mg}^{-1}$ which was 2.2 times higher than the $\mathrm{Pt}$ modified electrode. The good stability and higher turnover number further add merits to the GO-Pt nanostructures modified electrode. This study will contribute in developing the portable DFAFCs using Pt-based composite electrode materials.

\section{ACKNOWLEDGMENT}

RR acknowledges the financial support received from the CSIR Emeritus Scientist Scheme, New Delhi (No. 21(1006)/15/EMR-II). RP is the recipient of SRF from the Council of Scientific \& Industrial Research Emeritus Scientist Scheme.

\section{REFERENCES}

1. C.X. Xu, Y.Q. Liu, J.P. Wang, H.R. Geng and H.J. Qiu, "Nanoporous $\mathrm{PdCu}$ alloy for formic acid electro oxidation,” J Power Sources. 2012 vol.199, pp.124-131.

2. R. Yue, C. Wang, F. Jiang, H. Wang, Y. Du, J. Xu and P. Yang, "Electrocatalytic oxidation of formic acid on Pt Pd decorated poly fluorenes with hydroxyl and carboxyl substitution," Int J Hydrogen Energ. 2013, vol.38, pp. 12755-12766.

3. T. Maiyalagan, X. Dong, P. Chen and X. Wang, "Electrodeposited Pt on three-dimensional interconnected graphene as a free-standing electrode for fuel cell application,” J Mater.Chem. 2012, vol.22, pp.5286-5290.

4. H. Qiu, X. Dong, B. Sana, T. Peng, D. Paramelle, P. Chen and Sierin Lim, "Ferritin-Templated Synthesis and Self-Assembly of Pt Nanoparticles on a Monolithic Porous Graphene Network for Electrocatalysis in Fuel Cells," ACS Appl Mater Interfaces. 2013, vol.5, pp.782-787.

5. F. Ren, H. Wang, C. Zhai, M. Zhu, R. Yue, Y. Du, P. Yang, J. Xu and W. Lu, "Clean Method for the Synthesis of Reduced Graphene Oxide Supported PtPd Alloys with High Electrocatalytic Activity for Ethanol Oxidation in Alkaline Medium," ACS Appl Mater Interfaces, 2014 vol.6, pp.3607-3614.

6. S.S. John, P. Boolchand and A. P. Angelopoulos, "Improved Electrocatalytic Ethanol Oxidation Activity in Acidic and Alkaline Electrolytes Using Size-Controlled Pt-Sn Nanoparticles," Langmuir. 2013, vol.29, pp.16150-16159.

7. C. Rice, S. Ha, R.I. Masel and A. Wieckowski, "Catalysts for direct formic acid fuel cells," J Power Sources. 2003, vol.115, pp.229-235.

8. B.Z. Fang, M. Kim and J.S. Yu, "Hollow core/mesoporous shell carbon as a highly efficient catalyst support in direct formic acid fuel cell," Appl Catal B. 2008, vol.84, pp.100-105

9. J. Xu, D. Yuan, F. Yang, D. Mei, Z. Zhang and Y-X. Chen, "On the mechanism of the direct pathway for formic acid oxidation at a $\operatorname{Pt}(111)$ electrode," Phys Chem Chem Phys. 2013, vol.15, pp4367-4376.

10. H. Miyake, T. Okada, G. Samjeske and M. Osawa, "Formic acid electrooxidation on Pd in acidic solutions studied by surface-enhanced infrared absorption spectroscopy," Phys Chem Chem Phys. 2008, vol.10, pp.3662-3669.

11. J. Yang, C. Tian, L. Wang and H. Fu, "An effective strategy for small-sized and highly-dispersed palladium nanoparticles supported on graphene with excellent performance for formic acid oxidation," J Mater Chem. 2011, vol.21, pp.3384-3390.

12. C. Lim, R. Allen and K. Scott, "Effect of dispersion methods of an unsupported Pt-Ru black anode catalyst on the power performance of a direct methanol fuel cell," J Power Sources. 2006, vol.161, pp.11-18.
13. Y. Shao, J. Wang, M. Engelhard, C. Wang and Y. Lin, "Facile and controllable electrochemical reduction of graphene oxide and its applications," J Mater Chem. 2010, vol.20, pp.743-748.

14. C. Zhu, S. Guo, Y. Fang, L. Han, E. Wang and S. Dong, "One-step electrochemical approach to the synthesis of Graphene/MnO2 nanowall hybrids," Nano Res. 2011, vol.4, pp.648-657.

15. S. Stankovich, R.D. Piner, S.T. Nguyen and R.S. Ruoff, "Synthesis and exfoliation of isocyanate-treated grapheme oxide nanoplatelets," Carbon, 2006, vol.44, pp.3342-3347.

16. J. Pyun, "Graphene Oxide as Catalyst: Application of Carbon Materials beyond Nanotechnology," Angew Chem Int Ed. 2010, vol.50, pp.46-48.

17. S.T. Yang, Y.L. Chang, H.F. Wang, G.B. Liu, S. Chen, Y.W. Wang, Y.F. Liu and A.N. Cao, "Folding/aggregation of graphene oxide and its application in Cu2+ removal," J Colloid Interface Sci. 2010, vol.351, pp.122-127.

18. T.Y. Zhang, D. Zhang and M. Shen, "A low-cost method for preliminary separation of reduced grapheme oxide nanosheets," Mater Lett. 2009, vol.63, pp.2051-2054.

19. N. Zhang, H. Qiu, Y. Liu, W. Wang, Y. Li, X. Wang and J. Gao, "Fabrication of gold nanoparticle/graphene

20. oxide nanocomposites and their excellent catalytic performance," J Mater Chem. 2011, vol.21, pp.11080-11083. [20] S. Bong, Y. R. Kim, I. Kim, S. Woo, S. Uhm, J. Leeand H. Kim, "Graphene supported electrocatalysts for methanol oxidation," Electrochem Commun. 2010 vol.12,pp.129-131.

21. K. Niu, B. Yang, J. Cui, J. Jin, X. Fu, Q. Zhao and J.Zhang, "Graphene-based non-noble-metal $\mathrm{Co} / \mathrm{N} / \mathrm{C}$ catalyst for oxygen reduction reaction in alkaline solution," J PowerSources. 2013, vol.243, pp.65-71

22. Q. Wan, Y. Liu, Z. Wang, W. Wei, B. Li, J. Zou and N.Yang, "Graphene nanoplatelets supported metal nanoparticles for electrochemical oxidation of hydrazine,"Electrochem Commun. 2013 vol.29, pp.29-32

23. J-J. Lv, S-S. Li, J-N. Zheng, A-J. Wang, J-R. Chen, J-J.Feng, "Facile synthesis of reduced graphene oxide supported PtAg nanoflowers and their enhancedelectrocatalytic activity,” Int J Hydrogen Energ. 2014 vol.39, pp.3211-3218.

24. Y. Zhang, S. Liu, L. Wang, X. Qin, J. Tian, W. Lu, G. Chang and X Sun, "One-pot green synthesis of $\mathrm{Ag}$ nanoparticles-graphene nanocomposites and their applications in SERS, H2O2, and glucose sensing," RSCAdv. 2012, vol.2, pp.538-545.

25. Y. Choi , M. Gu, J. Park , H-K. Song and B-S. Kim, "Graphene Multilayer Supported Gold Nanoparticles for Efficient Electrocatalysts Toward Methanol Oxidation,"Adv Energy Mater. 2012, vol.2, pp. $1510-1518$

26. F. Xu, Y. Sun, Y. Zhang, Y. Shi, Z. Wen and Z. Li,“Graphene-Pt nanocomposite for nonenzymatic detection of hydrogen peroxide with enhanced sensitivity," ElectrochemCommun. 2011, vol.13, pp.1131-1134

27. J-P. Zhong, Y-J. Fan, H. Wang, R-X. Wang, L-L. Fan,X-C. Shen, Z-J. Shi, "Highly active $\mathrm{Pt}$ nanoparticles on nickel phthalocyanine functionalized graphene nanosheetsfor methanol electrooxidation," Electrochim Acta. 2013,vol.113, pp.653-660.

28. A. A. Ensafi, M. Jafari-Asl, B. Rezaei, "A new strategyfor the synthesis of 3-D Pt nanoparticles on reduced graphene oxide through surface functionalization,Application for methanol oxidation and oxygen reduction," Electrochim Acta. 2014, vol.130, pp.397-405.

29. W. Ye, H. Kou, Q. Liu, J. Yan, F. Zhou, C. Wang, “Electrochemical deposition of $\mathrm{Au}-\mathrm{Pt}$ alloy particles with cauliflower-like microstructures for electrocatalyticmethanol oxidation," Inter J Hydrogen Energy. 2012, vol.37, pp.4088-4097.

30. M. M. Shahid, P. Rameshkumar, A. Pandikumar, H. N. Lim, Y. H. Ng and N. M. Huang, An electrochemical sensing platform based on a reduced graphene oxide-cobalt oxide nanocube@platinumnanocomposite for nitric oxide. detection. J Mater Chem A. 2015, vol.3, pp.14458-14468. 


\section{AUTHORS PROFILE}

Dr. Perumal Rameshkumar is currently working as an Assistant Professor of Chemistry at Kalasalingam University, India. He obtained his M.Sc. (chemistry) (2009) from Madurai Kamaraj University. He joined as Junior Research Fellow (2010) at the same University and subsequently promoted as Senior Research Fellow (2012). His doctoral thesis focused on "polymer encapsulated metal nanoparticles for sensor and energy conversion applications. He worked as Post-Doctoral Research Fellow (2014) at University of Malaya, Malaysia in the field of "graphene-inorganic nanocomposite materials for electrochemical sensor and energy conversion applications". His current research interests include synthesis of functionalized nanomaterials, optical sensors, energy-related electrocatalytic processes, electrochemical sensors and supercapacitors. His research outcomes were documented in 25 peer reviewed journals including 01 review article and he edited 01 book under Elsevier publication.

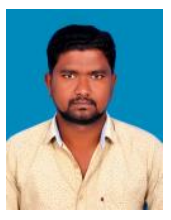

Mr. Raju Praveen obtained his M.Sc., degree in Chemistry (2012) from Periyar University, Salem, India. Currently, he is pursuing his Ph.D., programme in Chemistry under the guidance of Prof. R. Ramaraj in Department of Physical Chemistry, School of Chemistry, Madurai Kamaraj University, Madurai. His main areas of research interest include metal-metal oxide nanocomposite materials preparation and their modified electrodes for electrochemical sensors and solar energy conversion.

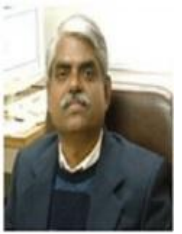

Prof. R. Ramaraj obtained his M.Sc., degree in Chemistry from Madurai Kamaraj University in 1980. He completed the Ph.D., degree in 1985 at University of Madras. Currently, he is a CSIR-Emeritus Scientist in Department of Physical Chemistry, Madurai Kamaraj University. His main areas of research interests include photoelectrochemistry, modified electrodes, nanomaterials, catalysis, photoelectrocatalysis, optical and electrochemical sensors, and solar energy conversion. 